\title{
ON A PROBLEM CONNECTED WITH STRONGLY CONVEX FUNCTIONS
}

\author{
MirosŁaW ADAMEK
}

Abstract. In this paper we show that the result obtained by Nikodem and Páles in [3] can by extended to a more general case. In particular, for a non-negative function $F$ defined on a real vector space we define $F$-strongly convex functions and show that such functions are in the form $g+F^{*}$, where $g$ is a convex function and $F^{*}$ is a function associated with function $F$, iff $F^{*}$ is a quadratic function. Using this result, we get a characterization of quadratic functions.

Mathematics subject classification (2010): Primary 46C15; Secondary 26B25, 39B62.

Keywords and phrases: Strongly convex function, strongly $F$-convex function, quadratic function.

\section{REFERENCES}

[1] J.-B. Hiriart-URruty AND C. LemaréChal, Fundamentals of Convex Analysis, Springer-Verlag, Berlin-Heidelberg, 2001.

[2] P. Jordan And J. V. Neumann, On inner products in linear metric spaces, Ann. Math. 36 (1935), $719-723$.

[3] K. Nikodem, Zs. PÁLes, Characterizations of inner product spaces by strongly convex functions, Banach J. Math. Anal. 5 (2011), no. 1, 83-87.

[4] B. T. POLYAK, Existence theorems and convergence of minimizing sequences in extremum problems with restrictions, Soviet Math. Dokl. 7 (1966), 72-75.

[5] A. W. Roberts and D. E. Varberg, Convex Functions, Academic Press, New York-London, 1973.

[6] J.-P. VIAL, Strong convexity of sets and functions, J. Math. Economics 9 (1982), 187-205. 